\title{
The scope for joint household/commercial collections: a case study
}

\author{
Fraser N. McLeod ${ }^{1}$, Tom J. Cherrett ${ }^{2}$ and Ben J. Waterson ${ }^{3}$ \\ Transportation Research Group, School of Civil Engineering and the Environment, \\ University of Southampton, United Kingdom.
}

${ }^{1}$ Telephone: +44 (0)23 80593316 (corresponding author)

Fax: +44 (0)23 80593152

E-Mail: F.N.McLeod@soton.ac.uk

${ }^{2}$ Telephone: $+44(0) 2380594657$

Fax: +44 (0)23 80593152

E-Mail: T.J.Cherrett@soton.ac.uk

${ }^{3}$ Telephone: $+44(0) 2380592345$

Fax: +44 (0)23 80593152

E-Mail: B.J.Waterson@soton.ac.uk

\section{Abstract}

\begin{abstract}
Although commercial and household wastes are compositionally similar, common UK practice is for separate collections. This paper uses vehicle routeing and scheduling software to predict the benefits of allowing household and commercial waste to be collected together by a common vehicle fleet. This was compared in a case study where collections were made from over 25,000 households on an alternate weekly basis and from 577 commercial premises having one or more collections each week. Modelled joint collections reduced vehicle mileage by up to $9.8 \%$, equating to an annual savings of around $£ 36,800$ and a carbon equivalent savings of $2688 \mathrm{~kg}$ per annum. The modelled benefits were greatest when a common starting time (6am) was adopted for the commercial and household collections. The modelled rounds were estimated to have sufficient time and vehicle capacity available to allow an additional 50\% of commercial waste to be collected, equating to 35.8 tonnes per week.
\end{abstract}

Keywords: waste collection, municipal, commercial

\section{Introduction}

The 'Waste Strategy for England’ report (Defra, 2007) highlighted the need for reducing the amount of waste generated by the commercial and industrial sectors. Commercial waste was estimated to comprise about 30 million tonnes/year compared with about 25 million tonnes/year for household waste (Defra, 2009). These waste volumes corresponded to $11 \%$ and $9 \%$ of all waste arisings, respectively, with the 
other main waste generating sectors being demolition/construction (32\%), mining/quarrying (30\%) and industrial (13\%). Under Section 34 of the 1990 Environmental Protection Act, commercial premises have a 'duty of care' to make satisfactory arrangements for their waste collection (Defra, 1990) and many different private contractors can provide this service: for example, it was found that 19 separate organisations collected residual waste, recyclate and other waste types from 76 businesses on Winchester High Street (Maynard and Cherrett, 2009). Most businesses pay National Non-Domestic Rates (NNDR) which do not cover the collection and disposal of waste by the local authority. Businesses are also not permitted to dispose of their waste at household waste recycling centres and therefore have a duty under the 1990 Environmental Protection Act to manage their waste responsibly. This is usually achieved by taking out a contract with a licensed waste contractor. Whilst some commercial waste may require specialist collection, a large proportion of it is similar in composition to household waste - with paper and cardboard comprising between 64\% and 74\% in some cases (McLeod et al., 2008) - and could be collected alongside the household waste.

Reforming the legal definition to integrate commercial waste into municipal waste could pave the way for more sustainable, co-ordinated collection practices (Coggins and McIlveen, 2009). Many small-to-medium enterprises (SMEs) currently find it difficult to find a local commercial waste recycling service that meets their needs as the collection of SME commercial waste for recycling is often not considered commercially viable by the larger waste contractors. DEFRA estimated that although $71 \%$ of SMEs currently undertake some form of recycling, 1.16 million SMEs are still not recycling any materials and there is therefore a market opportunity to set up commercial recycling services. Following the lead set by many of our 
European neighbours and reclassifying commercial waste in this way could allow local authorities to offer joint household-commercial collections which could have a significant impact in reducing waste collection vehicle activity in urban centres.

A typical High Street business can fulfil the requirements of the Producer PreTreatment Requirements (Biffa, 2009) by either separating out the recyclate (e.g. cardboard, paper, plastic, glass, metal) from the residual waste stream at source, by sending unseparated waste to either a sortation facility where recyclate can be recovered, or sending commingled waste to an 'energy-from-waste’ facility (incinerator). ('Residual waste' is defined as waste containing materials that have not been separated out or sent for reprocessing). Given these legal requirements, SMEs could benefit significantly by coordinating their activities with their neighbours in order to meet their legal obligations and reduce collection costs. Local authorities can also set up their own commercial waste collections, and under the Controlled Waste Regulations, can charge businesses for these services. DEFRA's, 'Consultation on meeting EU landfill diversion targets', launched on March $18^{\text {th }} 2010$, suggested that if the definition of municipal waste was to change, a lot of commercial waste, currently handled by the private sector, would come under the scope of the Landfill Directive (DEFRA, 2010). Commercial wastes count against an authority’s Landfill Allowance Trading Scheme (LATS) targets and there is therefore an incentive for authorities to better address the recycling or composting of biodegradable commercial waste and divert it from landfill.

An option already being used by some waste collection authorities (WCAs) is to utilise the existing household waste collection fleets to undertake joint household and commercial waste collections. This is not common practice because commercial 
waste has to be classified separately from household municipal waste under current UK law and does not contribute to a local authority's recycling targets. Waste disposal authorities (WDAs) may also charge WCAs considerably more for disposing of commercial waste than for household waste. There can also be issues of compatibility, not only in bin type and collection system used but in service frequency, with household collections occurring weekly and some commercial customers requiring service daily. New Forest District Council operates such a scheme where commercial waste is collected, as part of the household rounds, from SMEs who have pre-registered with the council and have acquired a 'duty of care' certificate. The WCA quantifies the weight of commercial waste collected by referring to the amount of specific commercial waste collection bags sold and by assuming a mean weight for a 100L bag of 8kg. For mixed use developments, particularly in historic city centres, such a scheme could reduce the number of refuse collection vehicles and the associated mileage travelled. Previous research looking at theoretical joint household/commercial collection rounds across the Hampshire WCAs of Hart and Rushmoor suggested that a commercial waste load of 3.9 tonnes/fortnight could be readily accommodated on the existing alternate weekly collection household rounds, without increasing the number of trips required to the waste disposal site (McLeod and Cherrett, 2007). This paper extends this research and provides a more detailed and comprehensive analysis of combining the existing household collection rounds with actual (not theoretical) commercial collections that are made in the city of Winchester, Hampshire.

\section{The Hampshire case study}

The modelled waste collection rounds used in the research represented approximately one half (the 'northern sector') of all household and commercial collections 
undertaken by a waste contractor on behalf of Winchester City Council. This collection area covered the city of Winchester and the surrounding areas, including Alresford, Kings Worthy, Otterbourne and Hursley (Figure 1). To give an indication of scale, the distance between the centres of Winchester and Alresford, shown in Figure 1, is approximately $13 \mathrm{~km}$. The contractor's vehicle depot was located in Winchester, only 1.3km from Winchester High Street (shown by the square in Figure 1). Both household and commercial waste was taken to a transfer station in Otterbourne, 8km from the High Street (shown by the triangle in Figure 1) which functioned between 8am and 4pm, Monday to Friday. Here, waste was stored, bulked and transported $31 \mathrm{~km}$ by a separate contractor to an energy-from-waste facility in Marchwood, Southampton; however, this final leg of the journey was not modelled in this research, as it would not be affected by the collection regime.

All data associated with the collection rounds were supplied by the waste contractor. These data included: 'weigh ticket' data, which provided the weight of waste disposed by each vehicle on each visit to the waste disposal site; and ordered lists of streets and properties visited on each vehicle round on each day of the week. The household waste data supplied covered a period of one year (2008); the commercial data supplied also covered a one-year period but, in this case, the data commenced from July 2008. 


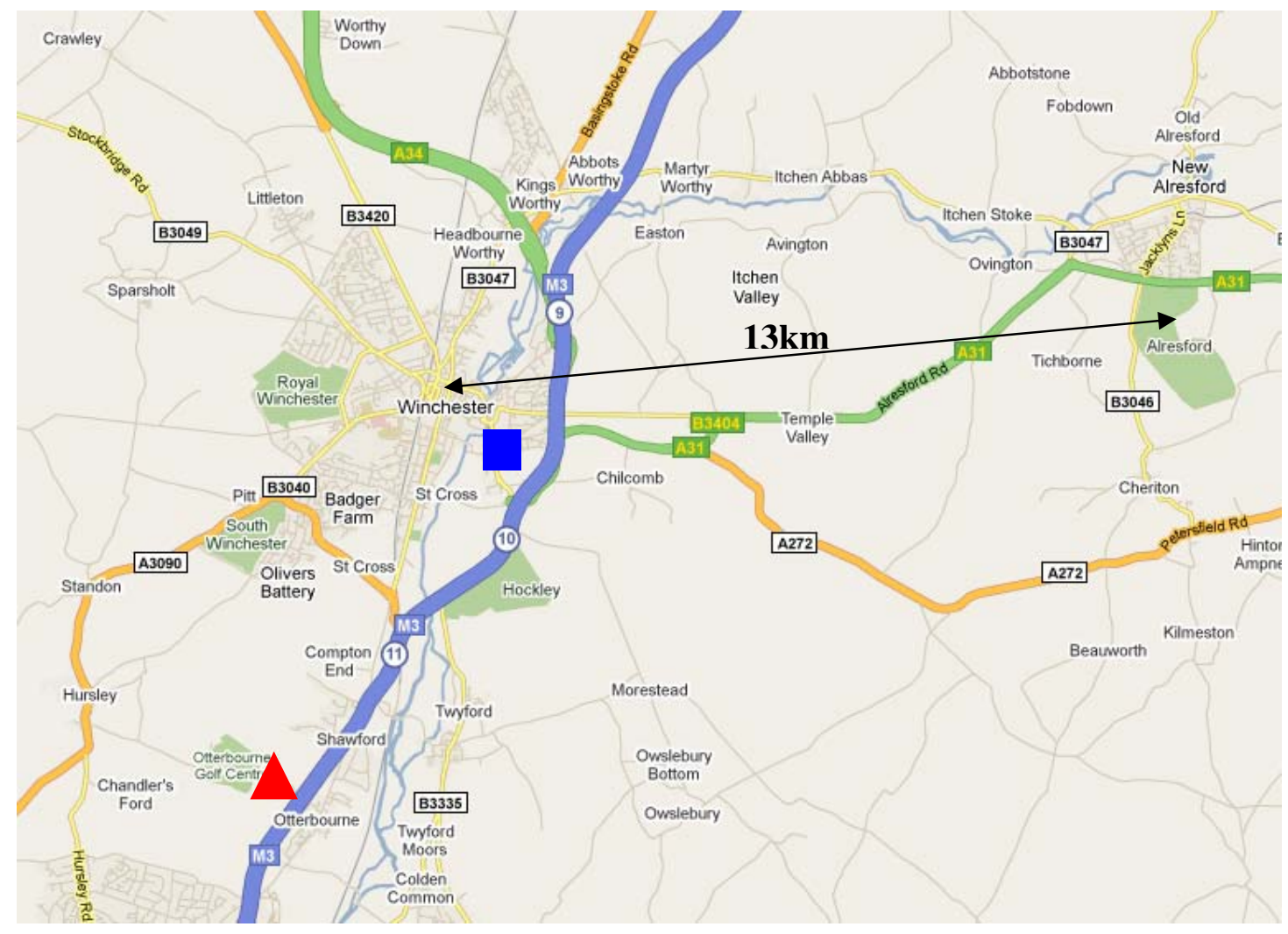

Figure 1. Map of the waste collection area (2009 Google - Map data (C2009 Tele Atlas). (Key: triangle $=$ transfer station; square $=$ vehicle depot $)$

\subsection{Household collections}

Household collections were made on an 'alternate weekly' basis, with households having their residual waste collected on one week and recyclate collected on the following week. A separate green waste collection round also operated. The 'recycling week' was the same for all households in the area, which meant that, in any given week, all the refuse collection vehicles (RCVs) would be collecting the same materials. This would have an impact on the round design for joint collections as commercial premises would need reliable daily coverage. For this study, only the collections of residual waste were modelled.

Collections were made from around 25,600 households, using five RCVs. The five RCVs corresponded to five rounds named '4', '5', '7', ‘4/6' and '5/7'. Four of these rounds collected residual waste five days a week (Monday to Friday), during the 
non-recycling weeks, while round $4 / 6$ collected residual waste on only four days (Monday to Thursday). The RCVs used had different carrying capacities (in tonnes (t)): 8.2t, 9.5t, 9.7t and 2x12.2t. The weights of waste collected on each round throughout the year (2008) were recorded, from which average weights per household per fortnight were derived for each round and for each day of the week (Table 1). The average weight per household per fortnight across all 5 rounds was $14.4 \mathrm{~kg}$ but there were significant differences between the rounds $\left(\mathrm{F}_{(4,118)}=118.4, \mathrm{P}<0.001, \mathrm{Ms}_{\mathrm{e}}=\right.$ 0.97). A Scheffe multiple range test suggested that, although collecting from the greatest number of households (5374, Monday to Thursday), round 4/6 encountered significantly lower mean weights of residual waste per household (11.2 kg/household) compared to all the other rounds. The majority of round 4/6 served houses in the centre of Winchester, a high proportion of which are small terraced properties. This contrasted to round 4 (16.4 kg/household) which served the largely detached residential areas off Andover Road, Stockbridge Road, Badger Farm and Oliver’s Battery.

The amount of waste generated by a household is influenced not only by the size of the household but also by the age profile of its members, with, for example, people over 60 producing more textile waste but less packaging (Jones et al., 2008). In terms of characteristics, Winchester City Council serves some 110,000 residents and the city has a slightly higher proportion of over 60s (23\%) compared to the national average. Levels of unemployment are low (1.3\%) and the area is affluent with some of the highest house prices in the region and half of the wards classed as within the least deprived $10 \%$ nationally.

Table 1. Average weight of residual waste collected for each fortnightly round in $\mathrm{kg}$ per household (Number of households on each collection round by day) 


\begin{tabular}{cccccccc}
\hline Round & Mon & Tue & Wed & Thu & Fri & $\begin{array}{c}\text { Mean } \\
\text { kg/hh }\end{array}$ & $\begin{array}{c}\text { Sig } \\
\text { Diff }^{1}\end{array}$ \\
\hline $\mathbf{4}$ & 17.7 & 16.8 & 16.7 & 14.3 & 16.7 & & \\
& $(1065)$ & $(1231)$ & $(1124)$ & $(1275)$ & $(1142)$ & $\mathbf{1 6 . 4}$ & e \\
\hline $\mathbf{5}$ & 16.3 & 12.0 & 17.0 & 18.4 & 15.5 & & \\
$\mathbf{7}$ & $(1037)$ & $(1439)$ & $(1233)$ & $(1106)$ & $(951)$ & $\mathbf{1 5 . 6}$ & d,e \\
\hline & 12.3 & 11.7 & 17.4 & 13.7 & 12.0 & & \\
$\mathbf{4} / \mathbf{6}$ & $(1254)$ & $(1203)$ & $(944)$ & $(879)$ & $(809)$ & $\mathbf{1 3 . 3}$ & $\mathbf{b}$ \\
\hline $\mathbf{5 / 7}$ & $(10.4$ & 11.1 & 11.2 & 11.8 & & & \\
\hline Overall mean & 15.3 & $(1608)$ & $(1317)$ & $(1337)$ & - & $\mathbf{1 1 . 2}$ & a \\
\hline
\end{tabular}

${ }^{1}$ Mean $\mathrm{kg}$ /household sharing the same letter are not significantly different $(\mathrm{p}=0.05)$ using Scheffe's multiple range test.

There was also considerable variability in the mean weights collected per household within rounds (Table 2) highlighting the fact that socio-demographic characteristics, housing type and area all impact on household waste arisings.

Research has suggested that the quantity of waste produced by a household can vary by up to $25 \%$ from week to week (Jones et al., 2008). Local authorities can therefore experience significant differences in waste arisings between neighbouring communities, not only in the material set out at kerbside but also that received through other mediums such as household waste recycling centres (Maynard et al., 2009a, 2009b). Such characteristics could impact on the potential RCV capacity available for commercial waste given the variability in household weights generated by different residential areas, and would need to be carefully considered when designing any joint household-commercial collection rounds.

Table 2. Average weight of residual waste collected by day of each round in kg per household per fortnight

\begin{tabular}{|c|c|c|c|c|}
\hline Round-Day & $\begin{array}{l}\text { No. of collections } \\
\text { (fortnightly) }\end{array}$ & $\begin{array}{l}\text { Mean } \\
\text { kg/hh }\end{array}$ & Variance & Scheffe $^{1}$ \\
\hline 4-Monday & 26 & 17.79 & 3.15 & $\mathrm{~b}$ \\
\hline 4-Tuesday & 26 & 16.80 & 6.00 & $\mathrm{~b}$ \\
\hline 4-Wednesday & 26 & 16.73 & 1.39 & $\mathrm{~b}$ \\
\hline 4-Thursday & 26 & 14.25 & 1.52 & $\mathrm{a}$ \\
\hline 4-Friday & 25 & 16.73 & 1.29 & $\mathrm{~b}$ \\
\hline
\end{tabular}


$\left(\mathrm{F}_{(4,124)}=16.7, \mathrm{P}<0.001, \mathrm{Ms}_{\mathrm{e}}=2.68\right)$

\begin{tabular}{lllll}
\hline Round-Day & $\begin{array}{l}\text { No. of collections } \\
\text { (fortnightly) }\end{array}$ & $\begin{array}{l}\text { Mean } \\
\text { kg/hh }\end{array}$ & $\begin{array}{l}\text { Variance } \\
\text { Scheffe }\end{array}$ \\
5-Monday & 26 & 16.34 & 2.68 & bc \\
5-Tuesday & 25 & 12.00 & 0.64 & a \\
5-Wednesday & 26 & 17.01 & 0.76 & C \\
5-Thursday & 26 & 18.39 & 7.03 & d \\
5-Friday & 25 & 15.45 & 0.85 & b \\
\hline$\left(\mathrm{F}_{(4,123)}=60.25, \mathrm{P}<0.001, \mathrm{Ms}_{\mathrm{e}}=2.42\right)$ & & &
\end{tabular}

\begin{tabular}{|c|c|c|c|c|}
\hline Round-Day & $\begin{array}{l}\text { No. of collections } \\
\text { (fortnightly) }\end{array}$ & $\begin{array}{l}\text { Mean } \\
\text { kg/hh }\end{array}$ & Variance & Scheffe $^{1}$ \\
\hline 7-Monday & 26 & 12.30 & 1.38 & $\mathrm{a}$ \\
\hline 7-Tuesday & 25 & 11.72 & 0.55 & $\mathrm{a}$ \\
\hline 7-Wednesday & 26 & 17.36 & 1.01 & $b$ \\
\hline 7-Thursday & 25 & 13.68 & 2.16 & c \\
\hline 7-Friday & 25 & 12.00 & 0.64 & $\mathrm{a}$ \\
\hline
\end{tabular}

\begin{tabular}{|c|c|c|c|c|}
\hline Round-Day & $\begin{array}{l}\text { No. of collections } \\
\text { (fortnightly) }\end{array}$ & $\begin{array}{l}\text { Mean } \\
\text { kg/hh }\end{array}$ & Variance & Scheffe $^{1}$ \\
\hline 4/6-Monday & 25 & 10.42 & 0.88 & $\mathrm{a}$ \\
\hline 4/6-Tuesday & 26 & 11.07 & 1.59 & $a b$ \\
\hline 4/6-Wednesday & 26 & 11.26 & 3.23 & $\mathrm{ab}$ \\
\hline 4/6-Thursday & 26 & 11.83 & 0.50 & C \\
\hline
\end{tabular}

\begin{tabular}{|c|c|c|c|c|}
\hline Round-Day & $\begin{array}{l}\text { No. of collections } \\
\text { (fortnightly) }\end{array}$ & $\begin{array}{l}\text { Mean } \\
\text { kg/hh }\end{array}$ & Variance & Scheffe $^{1}$ \\
\hline 5/7-Monday & 26 & 15.26 & 11.21 & $\mathrm{a}$ \\
\hline 5/7-Tuesday & 25 & 12.88 & 1.55 & b \\
\hline 5/7-Wednesday & 26 & 18.35 & 4.74 & c \\
\hline 5/7-Thursday & 26 & 19.28 & 0.52 & c \\
\hline 5/7-Friday & 25 & 12.37 & 4.45 & $\mathrm{~b}$ \\
\hline
\end{tabular}

${ }^{1}$ Mean $\mathrm{kg} /$ household sharing the same letter are not significantly different $(\mathrm{p}=0.05)$ using Scheffe's multiple range test.

An analysis of the residual weights produced by month suggested that there was a significant difference in the mean weight per household per collection between January (16.6 kg/household/collection) and December (13.5 kg/household/collection) $\left(\mathrm{F}_{(11,603)}=3.12, \mathrm{P}<0.001, \mathrm{Ms}_{\mathrm{e}}=9.4\right)$ using a Scheffe multiple range test (Figure 2). This relates to the volume of material generated over the Christmas period which is set out for collection at the beginning of the New Year. 


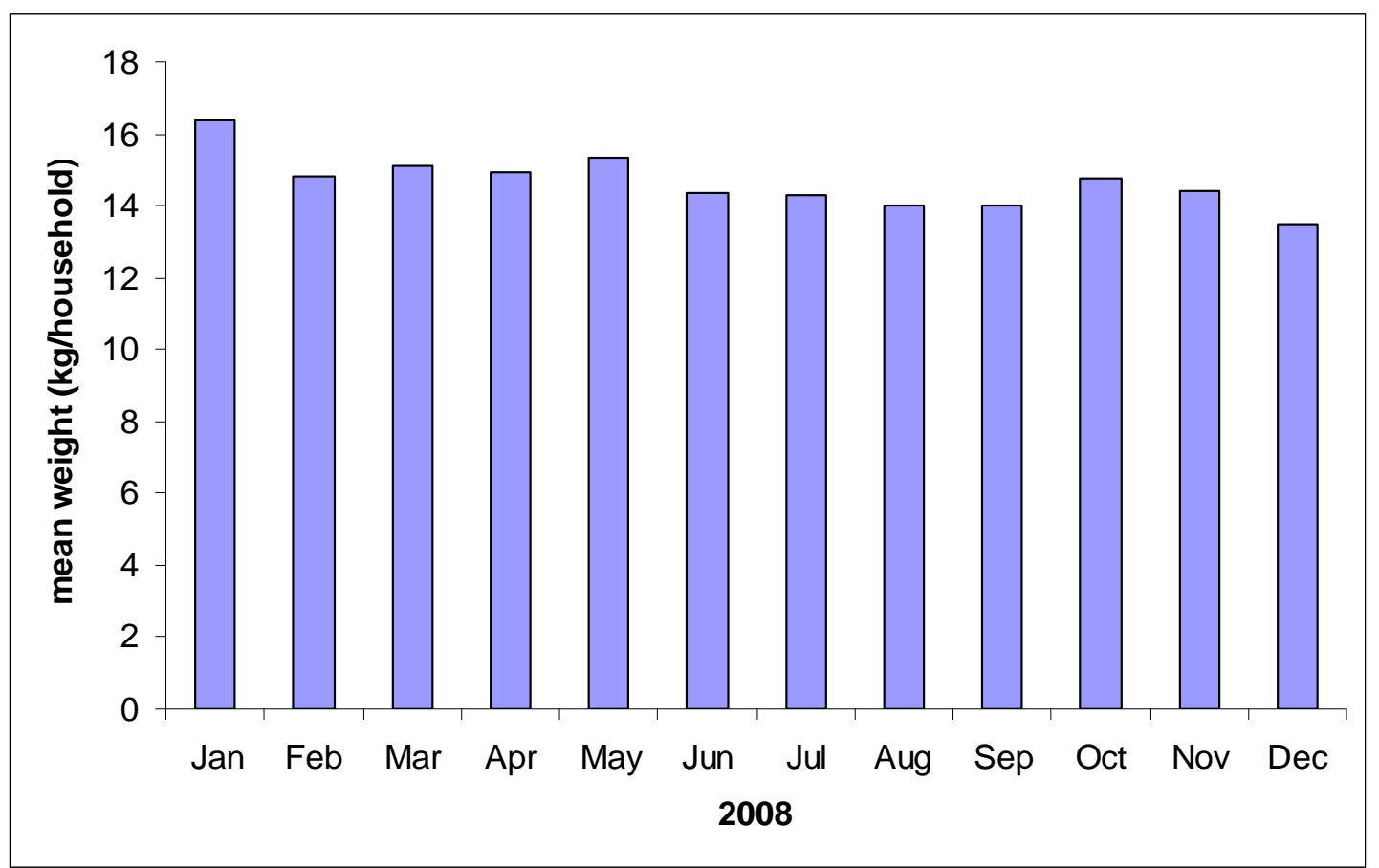

Figure 2. Mean set out weight of residual waste per household per collection by month (kg).

\subsection{Commercial collections}

Mixed recyclable and residual wastes were collected from 577 different commercial premises. This was done separately from the household collections, using an RCV with a carrying capacity of approximately 8.9t. The vast majority of premises (490 of the 577) required a single collection each week, while the others had either two (44), three (26) or more (17) collections each week. Of those premises having two collections per week, the most popular days were Monday and Thursday. Businesses receiving three collections per week did so most commonly on Monday, Wednesday and Friday and the data showed that Monday was the busiest day of the week, followed by Wednesday and Friday in terms of the number of bins/sacks collected (Table 3). A variety of sacks and bins were used for the commercial collections (Figure 3) with the most common receptacles being 1100L paladin bins and 240L wheelie bins. The average bin/sack capacity was 623L and the average number of containers emptied per premise per week was 2.4 (=1381 / 577). For some premises, 
the number of sacks used was not specified in the data; and in these cases, the average figure of 2.75 sacks per collection, derived from other commercial premises, was assumed.

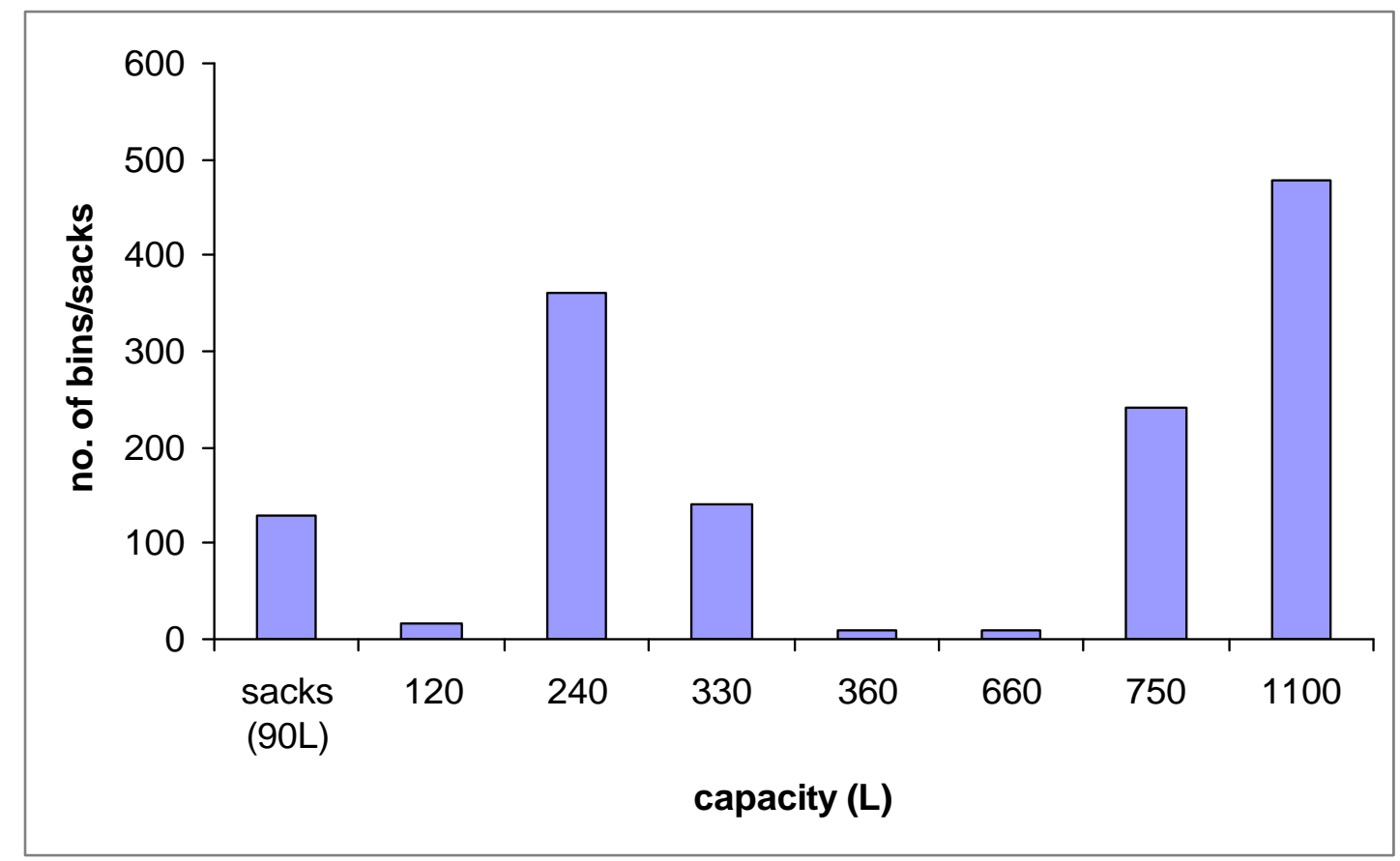

Figure 3. Number of bins/sacks set out across the five days of the commercial round.

The bin and sack volumes at each commercial address were used to apportion the average weight collected (Table 3) among the commercial premises. Commercial premises having the same postcode in the database were consolidated and treated as a single collection point when scheduling the collection rounds.

Analysis of the commercial round data suggested that there were significant differences between collection days in both the total tonnages lifted and the mean weight per bin/sack ( $\mathrm{kg}$ ) of the premises making up each daily round (Table 3). The Monday round recorded the greatest tonnage (19.5 tonnes), significantly heavier than the other collection days, but did not result in the greatest mean weight per bag/sack (51 kg) as more were set out (380). The Thursday round experienced the lowest set out but recorded the highest mean bin/sack weight $(70 \mathrm{~kg})$. 
Table 3. Numbers of bins or sacks collected on each day and total weight lifted

\begin{tabular}{|ccccccccc|}
\hline Day & $\begin{array}{c}\text { No. } \\
\text { of } \\
\text { days }\end{array}$ & $\begin{array}{c}\text { No. } \\
\text { bins/ } \\
\text { sacks }\end{array}$ & $\begin{array}{c}\text { Total } \\
\text { Weight } \\
\text { (t) }\end{array}$ & Var. & Scheffe ${ }^{1}$ & $\begin{array}{c}\text { Mean } \\
\text { weight } \\
(\mathrm{kg} / \mathrm{bin} \\
\text { or sack) }\end{array}$ & Var. & $\begin{array}{c}\text { Scheffe } \\
2\end{array}$ \\
Mon & 48 & 380 & 19.5 & 18.3 & a & 51.3 & 126.8 & b \\
Tue & 50 & 235 & 13.8 & 15.8 & b & 58.7 & 287.0 & c \\
Wed & 51 & 308 & 13.0 & 4.6 & b & 42.2 & 48.3 & a \\
Thu & 49 & 187 & 13.0 & 2.4 & b & 69.5 & 69.8 & d \\
Fri & 51 & 271 & 12.3 & 9.1 & b & 45.4 & 124.2 & ab \\
\multicolumn{2}{l}{ Total } & $\mathbf{1 3 8 1}$ & $\mathbf{7 1 . 6}$ & & Mean & $\mathbf{5 1 . 8}$ & & \\
${ }^{1}\left(\mathrm{~F}_{(4,244)}=42.8, \mathrm{P}<0.001, \mathrm{Ms}_{\mathrm{e}}=9.9\right)$ \\
${ }^{2}\left(\mathrm{~F}_{(4,244)}=46.1, \mathrm{P}<0.001, \mathrm{Ms}_{\mathrm{e}}=131.1\right)$ & & & & & &
\end{tabular}

In terms of the commercial waste collected by month, no significant

differences were found between individual months in terms of the total tonnes

collected $\left(\mathrm{F}_{(11,237)}=1.56, \mathrm{P}=0.11, \mathrm{Ms}_{\mathrm{e}}=16.3\right)$ or in terms of the mean weight of the bins or sacks set out for collection $\left(\mathrm{F}_{(11,237)}=0.95, \mathrm{P}=0.49, \mathrm{Ms}_{\mathrm{e}}=227\right)$. When looking at the data by quarter (Figure 4), the pre-Christmas period from October to December generated significantly more waste (approximately 951 tonnes, 79 tonnes per week) compared to the other three quarters (January-March, 69 tonnes/week; April-June, 66 tonnes/week; July-September, 69 tonnes/week), $\mathrm{F}_{(3,41)}=9.9, \mathrm{P}<0.001, \mathrm{Ms}_{\mathrm{e}}=38.1$.

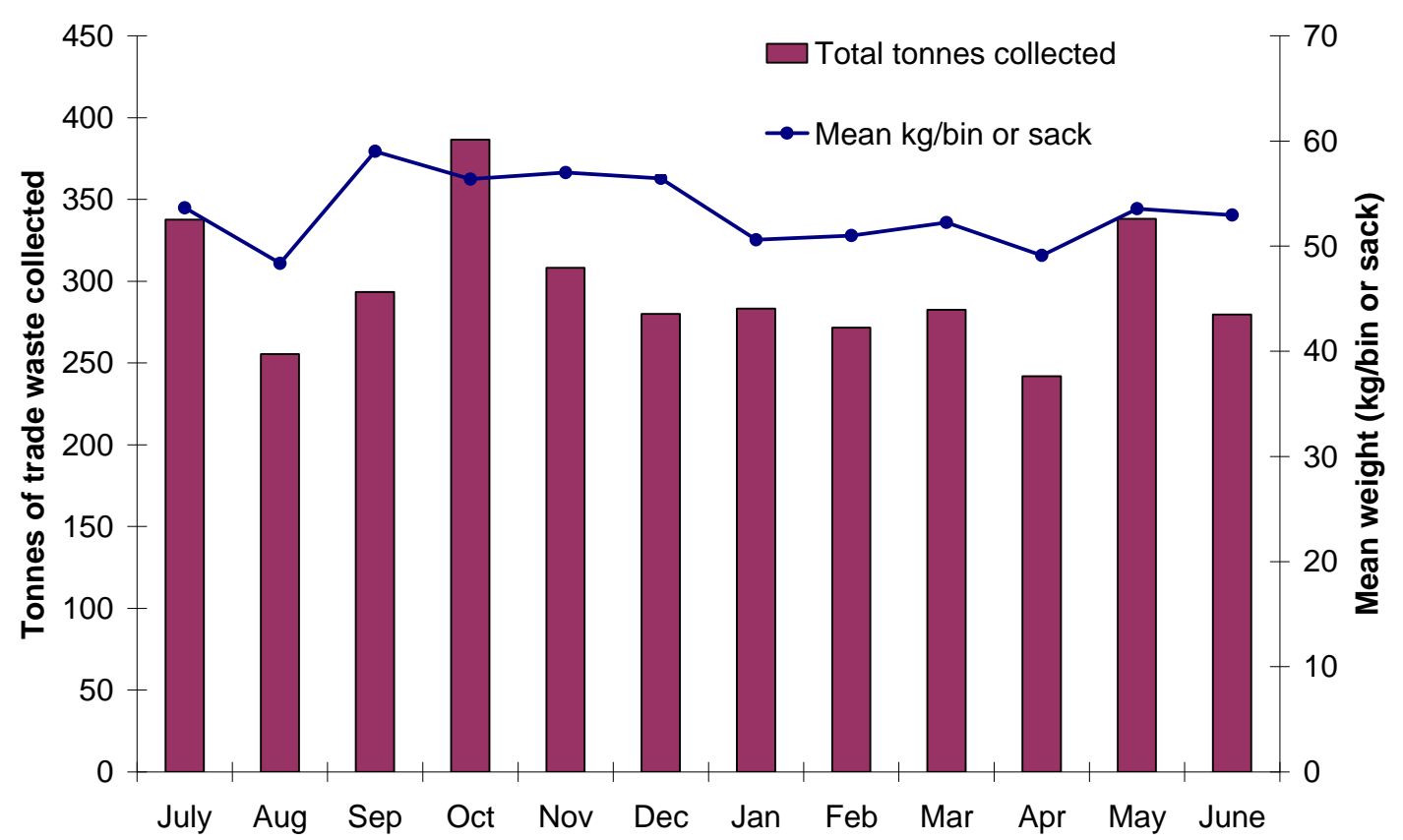


Figure 4. Tonnes of commercial waste set out by month and the mean receptacle weight.

\subsection{Issues associated with joint household and commercial collections}

A consideration when designing joint household-commercial collection rounds is to what extent peak waste generation periods coincide across the two sectors. The evidence from the case study suggested that the main household peak falls immediately after Christmas with the commercial sector achieving peak output in the build up to Christmas, implying that vehicle capacity may not be adversely affected by a 'combined' peak period.

A local authority interested in investigating joint household/commercial collections must first assess the suitability of their current operations. Particular problems and constraints can relate to:

(1) The current household waste collection system. Such a concept is not suitable when a 'kerbside sort' system is being used for household waste collections. Where mixed waste is collected in bins, there can be the added complication of household rounds being undertaken on an alternate weekly basis, with residual waste (refuse) collected on one week and recyclate on the other, whereas commercial premises can receive collections, one or more times each week. In the case of the Winchester case study, this was further complicated in that the existing household rounds had been designed so that the 'recycling weeks' and 'refuse weeks' were the same for all households. This meant that during the recycling weeks there would be no household vehicles available to collect the mixed commercial waste (as the recyclable waste cannot be contaminated). As a result, the modelled joint collection rounds had to be substantially redesigned.

Analysis of household round data undertaken as part of this case study suggests that there can be significant variability between collection rounds and between the days within individual collection rounds. The demographics of the collection area, the housing mix and the land use can all impact on waste generation rates and it is important to understand which current household rounds might struggle to accommodate additional collections due to consistent variability in waste volumes. To effectively cater for commercial premises, one would need guaranteed vehicle capacity, particularly during peak business periods. Closer inspection of the weigh ticket data might rule out some household rounds as being unsuitable for a joint collection system.

(2) The existing commercial collection system. Existing commercial collection rounds may commence from 06:00 whereas household collections may not start 
before 07:00 depending on local access restrictions. In the case of Winchester, the latter restriction is imposed by Winchester City Council to avoid noise and disturbance to residents. However, an earlier starting time for commercial waste is permitted and is employed by the waste contractor to avoid traffic and parking problems in the city centre. This difference in starting times makes it more difficult to design efficient round schedules for joint household and commercial waste collection, and this aspect of the problem was investigated as part of this study.

(3) Special consideration for certain commercial premises. Commercial waste rounds are often quite complex in structure due to the specific collection requirements of the clients which may entail specific collection times, multiple collections, collection from different points and different types of receptacle. In the Winchester study, there were some commercial premises who had to be visited early in the morning (06:00-07:45) to ensure that access to their bins was possible, as traffic and parked vehicles could create difficulties later in the day. Other premises could not be serviced before they had been unlocked, typically just before 09:00. This meant that time window constraints were applied to the collection problem.

\section{Methodology}

Vehicle rounds were modelled with the aid of commercially-available routeing and scheduling software that included street-level mapping to allow detailed routes to be calculated. This software also permitted user-specified time penalties to be applied to certain roads at certain times of day which enabled schools and main roads to be avoided at peak times. The modelled rounds were based on the average volume of waste collected on each of the existing rounds, derived from the weigh ticket data.

The existing household collection rounds were supplied by the waste contractor as lists of street names in approximate round order. These were converted to lists of postcodes, with each postcode then representing a collection point within the routeing/scheduling model. The collection rounds comprised a total of 1,442 postcodes. With drivers free to vary their routes from week to week, the existing routes could not be specified. Consequently, the optimal route around the postcodes for each round/day was assumed as a base case. A similar procedure was undertaken 
for the commercial round, which was supplied as non-ordered lists of commercial premise addresses.

It should be noted that the waste collection problem being tackled here is typically too large and complex to find an optimal solution (Toth and Vigo, 2002, Cordeau et al., 2007); however, such software is able to find routes and schedules that are normally better than existing ones derived manually. As the aim of the research was to evaluate waste collection strategies rather than to develop vehicle routeing and scheduling algorithms, the software was used, as is, accepting the limitations associated with using vehicle routeing and scheduling software (McLeod and Cherrett, 2011).

\subsection{Calibrating round times}

The main model parameters affecting round times were loading times (at the waste collection points), vehicle speeds, and unloading times (at the waste disposal site). The modelled round times were compared with actual round times that were recorded for a one-week period, with adjustments being made to the assumed loading time parameter values.

\subsubsection{Loading times}

In reality, the loading time at each collection point (postcode) is a complex function of the walking distances from the vehicle to the bins, the time taken to empty a bin, typically using automatic lifting equipment, the number of households/commercial premises at the postcode, the proportion of households setting their bin out for collection, the weights of bins (heavier ones are more difficult to drag) and, perhaps some other factors too. However, the only information available to this study were the numbers of properties and the weights of waste lifted on the round, so loading times were estimated in terms of the time needed per bin or per weight of waste collected. 
After this calibration process, the following loading time values were derived for use in the model:

- $0.5 \mathrm{~s} / \mathrm{kg}+7 \mathrm{~s} /$ household, for household waste

- $0.6 \mathrm{~s} / \mathrm{kg}+40 \mathrm{~s} /$ premise, for commercial waste

where the weight of waste collected at each postcode was allocated on a pro-rata basis, according to the number of properties at the postcode.

\subsubsection{Vehicle speeds}

The software's default values for heavy goods vehicle travel speeds were assumed, where these data were derived from UK Freight Transport Association statistics. Speeds varied between road types and whether the roads were urban or rural. As an example, the average HGV speed on city centre roads was $17 \mathrm{kph}$. It should be noted that these speeds were used to calculate travel time between collection points (postcodes). In practice, the travel speed within a collection point (postcode) may be less than this (e.g. walking pace), however, this was subsumed within the modelled time for loading the waste.

\subsubsection{Unloading times}

The unloading time at the waste disposal site was assumed to be a fixed value of 20 minutes, based on advice from the waste collection manager. In practice, this time can vary depending on the number of vehicles at the site. For example, a survey of 628 vehicle trips at a landfill site near Southampton gave an average turnaround time of 11 minutes (Mazzotti, 2004). Modelling variable unloading times has been attempted previously (Bhat, 1996) but was not undertaken here.

\subsection{Performance measures}

The main performance criteria used in this case study were the round times, distances travelled, vehicle days worked and the number of loads taken to the waste disposal 
site. Since round times are dominated by the assumed fixed loading time (60\%-75\%

of the round time is due to loading time), percentage savings will be greater for travel distances than for round times.

\subsection{Combining commercial and household waste collections}

To allow commercial and household waste collections to be combined under the existing 'alternate weekly collection' arrangement it was necessary to redesign the rounds to ensure that some household residual waste collections were undertaken in each week (currently no household residual waste collections take place in alternate weeks). The approach taken in this study was to divide the collection area into two parts with one part receiving its residual waste collections in 'week 1' and the other part in 'week 2'. Since five existing residual waste rounds were modelled, the collection area was divided to give an approximate 60/40 split in the work to be done, with three RCVs being assigned to 'week 1' and two RCVs assigned to 'week 2', in addition to the existing 'commercial' RCV being used in both weeks. The division was made arbitrarily, according to postcode areas. Further research would be required to assess how different divisions of the area would affect the results.

\section{Results}

The results of the modelling are presented for three scenarios involving separate household and commercial collections (denoted S1, S2 and S3) and two joint collection scenarios (denoted J1 and J2) (Table 4). The scenarios were:

(1) Optimal round order only (S1) - The round order for each round and day was optimised but maintaining the existing collection day and vehicle for all households and commercial premises.

(2) Optimal round structure for each day of the week (S2)- The household waste round structures for each day of the week were optimised separately. This meant that households would be visited on the same days as before but perhaps by a different collection crew. The commercial round could not be optimised in this way here, as there was only one collection crew. 
(3) Round structure optimised over all days (S3) - The household waste round structures were optimised over all days. This meant that the collection day for some households changed. The commercial round could, in principle, also be optimised in this way, but only if there was scope to change the collection days for some premises. This possibility was not investigated here - all commercial collections were made on the same days as before, according to the client contracts.

(4) Existing start times (different for household and commercial) (J1) - The existing council rules require that household collections may not be made before 07:00, for noise/disturbance reasons, while commercial collections start from 06:00.

(5) Common start time for both household and commercial (J2) - Household collections were allowed to start from 06:00 to align with the commercial collections. It should be noted that a common start time of 07:00 would not have been possible due to the time window constraints associated with some of the commercial collections.

Table 4. Comparison of results

\begin{tabular}{|c|c|c|c|c|c|c|c|}
\hline \multirow{2}{*}{ Scenario } & \multicolumn{4}{|c|}{ Sum of all rounds in a two-week period } & \multicolumn{3}{|c|}{$\begin{array}{l}\text { Round time statistics } \\
\text { (hours:mins) }\end{array}$} \\
\hline & $\begin{array}{l}\text { Time } \\
\text { (hours:mins) }\end{array}$ & $\begin{array}{l}\text { Distance } \\
(\mathbf{k m})\end{array}$ & $\begin{array}{l}\text { Vehicle } \\
\text { days }\end{array}$ & Loads & Mean & Min & $\operatorname{Max}^{1}$ \\
\hline $\mathrm{S} 1$ & 232:04 & 2171.1 & 34 & 69 & $6: 49$ & $3: 46$ & $7: 42^{*}$ \\
\hline $\mathrm{S} 2$ & $227: 15$ & 2096.3 & 32 & 61 & $7: 06$ & $3: 28$ & $7: 58^{*}$ \\
\hline S3 & $226: 42$ & 2055.5 & 33 & 60 & $6: 52$ & $4: 10$ & $7: 51^{*}$ \\
\hline $\mathrm{J} 1$ & $225: 55$ & 2039.9 & 35 & 62 & $6: 27$ & $3: 34$ & $7: 57$ \\
\hline $\mathrm{J} 2$ & $223: 29$ & 1958.9 & 35 & 60 & $6: 23$ & $3: 53$ & $7: 57$ \\
\hline
\end{tabular}

${ }^{1}$ Maximum values are for the household rounds only. The commercial round on a Monday was modelled to take over 10 hours.

Comparing the round times and distances of the separate collection scenarios (S1, S2 and S3) indicates the potential benefits available through optimisation. For example, the full optimisation (S3) reduced the total round time by $2.3 \%$ and the distance travelled by 5.3\%. The estimated round times and distances for the joint collection scenarios were lower still, suggesting that joint commercial and household collections are worthwhile considering. The joint collection scenario which allowed a common start time (06:00) for the commercial and household collections (J2) performed better than the scenario where household collections could not start until 07:00. This was expected, as a common start time permits greater flexibility in the round design. The greatest benefit found was a distance savings of $9.8 \%$ and a time savings of 3.7\% when the joint collection scenario J2 was compared with the separate 
collection scenario S1. This equated to a potential cost savings of around $£ 36,800$ per annum, based on vehicle operating costs of $£ 132,500$ that were estimated for a 26tonne gross vehicle weight RCV with driver and two loaders. Carbon equivalent savings of 2688kg per annum were estimated, based on the reduced mileage and a fuel consumption rate of $1.5 \mathrm{~km} /$ litre (Jacobs Babtie, 2005). It should be noted that distance savings were proportionally greater than time savings due to the fact that a large proportion (60\%-75\%) of the round time, corresponding with loading waste, was assumed to be irreducible.

The numbers of vehicle loads taken to the waste disposal site (Table 4) were similar (60-62 loads) between the optimised separate collections and the joint collections, compared with the 69 loads modelled for the existing round design. The numbers of vehicle days required to do the work were reduced from 34 to 32 or 33 for the optimised separate collection scenarios (S2 and S3) but increased to 35 for both joint collection scenarios (J1 and J2). However, the average round times were lowest for the joint collection scenarios. The full complement of 35 vehicle days work (= (4 vehicles (week 1) + 3 vehicles (week 2)) x 5 days of the week) were required for the joint collections due to the constraints imposed by the commercial collections, namely 06:00-07:45 time windows for some premises and specified collection days for all premises.

The modelled joint collection rounds with a common 06:00 start time were estimated to have sufficient time and vehicle capacity available to allow an additional $50 \%$ of the current commercial waste volume (35.8T per week) to be collected. This equated to an additional 690 commercial bins/sacks, or around 288 additional commercial premises per week. This additional weight would be equivalent to $1.79 \mathrm{~T}$ 
per vehicle per day in one week and 2.39T per vehicle per day in the second week, with the difference due to the fact that collections were made by four vehicles in week one and only three vehicles in week two. However, the amount of extra commercial work that could be accommodated on the rounds would be limited by the time window requirements of any new commercial premises and also the waste collection manager may want to have some spare capacity in the round design to be able to cope with random increases in the amount of waste to be collected from week to week. Despite these issues, there appears to be considerable scope for such a system to specifically target small-to-medium sized businesses and potentially reduce the amount of refuse collection vehicle traffic in the city centre.

\section{Conclusions}

This paper has demonstrated the time and distance savings that may be gained from permitting a co-ordinated commercial waste and household waste collection service, using a case study in Winchester. It has demonstrated that the modelled joint collection rounds had sufficient time and vehicle capacity available to allow an additional $50 \%$ of the current commercial waste volume (35.8T per week) to be collected, equating to an additional 690 commercial bins/sacks per week.

These findings are timely and relevant, given the recent UK government commercial and industrial (C\&I) waste strategy which emphasises the role local authorities could play in providing innovative commercial waste collection schemes (Defra, 2009). It has also been recently advocated that reforming the legal definition to integrate C\&I waste into municipal waste could pave the way for more sustainable, co-ordinated collection practices of this type (Coggins and McIlveen, 2009) which could particularly benefit SMEs. 
The modelled savings were largely due to the increased efficiency associated with combining the work. A vehicle distance savings of $4.7 \%$ was achieved when compared with a fully optimised base case scenario; however, this result required that the commercial and household collections be permitted to start at the common time of 06:00. The modelled benefits reduced to only $0.8 \%$ when the existing restriction of a 07:00 start time for household waste was enforced. A common start time of 07:00 would not have been possible due to time window constraints applied to some commercial premises.

Other practical implementation problems that may be encountered relate to differences in collection frequencies and in the materials collected. In the case study example, households had alternate weekly collections of residual waste and recyclable waste whereas commercial premises had weekly, or more frequent, collections of mixed waste. The approach taken here was to redesign the rounds to ensure that there were at least three vehicles collecting residual waste each week and the commercial collections were assigned to different collection rounds in each of the alternate weeks. This was necessary as the existing collection arrangement meant that there were no household vehicles collecting residual waste during the 'recycling week'. A potential disadvantage of splitting the residual waste collections between the two weeks in this way is that there would be reduced vehicle cover in the event of a vehicle breakdown, as the vehicles collecting recyclable waste could not come to the assistance of those collecting residual waste, and vice versa. A potential disadvantage of having the commercial collections made by different collection crews in each alternate week is that it might become more difficult to organise if any commercial collections have to be carried over from one week to the next, for whatever reason. 
An alternative approach would be to require that commercial premises separate their recyclable waste from their residual waste and collect the waste types separately. These collections could be made either on an alternate weekly basis, which may not be acceptable for commercial premises with high waste volumes, and/or insufficient storage space, or due to health concerns, particularly related to food waste, or weekly collections could be made.

While current UK legislation does not provide much incentive for waste collection authorities to make joint collections of commercial and household waste, this may change in the future once the wider recycling and operational benefits are recognised. Of particular interest is the potential for such joint household/commercial systems to actively involve SMEs who can often be excluded from the commercial waste contract system due to the small and variable volumes of recyclate produced. Such a service could generate additional income for the waste collection authority and better utilise the existing household waste collection fleet. There are however, many issues that would need to be addressed in planning such a service, particularly the issue of spare capacity to handle peak periods and times of vehicle breakdown, and the difficulties that might arise in setting up new contracts and adapting existing ones based on the domestic services.

Biographical notes

Fraser McLeod, B.Sc., M.Phil. is a Research Fellow with the Transportation Research Group, University of Southampton, UK with over 20 years experience of working on transport projects. In recent years he has specialised in Intelligent Transport Systems research and evaluation, particularly in connection with freight distribution, public transport, urban traffic control, pedestrian behaviour and control. Recent studies have investigated the transport associated with home shopping deliveries and with waste collection.

Tom Cherrett, B.Sc., Ph.D, MCILT is a Senior Lecturer in the Transportation Research Group within the School of Civil Engineering and the Environment, University of Southampton, UK. His main research areas include developing sustainable strategies for the collection and disposal of wastes and the distribution of goods in urban areas, including distribution strategies for sustainable home delivery. He also has considerable experience in the areas of incident detection and journey time estimation 
using urban traffic control infrastructure and management and logistics experience from working in the chilled distribution sector.

Ben Waterson, B.Sc., M.Sc., Ph.D, is a lecturer in the Transportation Research Group within the School of Civil Engineering and the Environment, University of Southampton, UK. He specialises in the monitoring of traffic patterns through the interpretation and analysis of real-time traffic data and the simulation of Intelligent Transport Systems, particularly traveller information systems and the effects that behavioural responses to such systems have on the transport network as a whole. The current focus of his research is on the cross-referencing and fusion of diverse urban transport data sources and utilisation of new forms of real-time data in traffic optimisation.

\section{References}

Bhat, V.N., 1996. A model for the optimal allocation of trucks for solid waste management. Waste Management and Research, 14, 87-96.

Biffa, 2009. The UK Landfill Regulations Pre-treatment Requirements [online]. Available from: http://www.biffacorporate.co.uk/pre-treatmentrequirements.aspx [Accessed date: 3 December 2009]

Coggins, C., McIlveen, R., 2009. A wasted opportunity? How to get the most out of Britain's bins [online], Available from http://www.policyexchange.org.uk/images/publications/pdfs/A_wasted_opport unity_1.pdf [Accessed date: 19 July 2010]

Cordeau, J.-F., Laporte, G., Savelsbergh, M. W. P. and Vigo, D., 2007. Vehicle Routing. In: Barnhart, C. and Laporte, G., eds. Handbooks in Operations Research and Management Science, Vol. 14. Amsterdam: Elsevier, 367-428.

Defra (1990). Waste Management, The Duty of Care: A Code of Practice. Environmental Protection Act 1990, Section 34.

Defra (2007). Waste Strategy for England 2007 [online]. Available from http://www.defra.gov.uk/ environment/waste/strategy/index.htm. [Accessed date: 19 July 2010]

Defra (2009). Commercial and Industrial waste in England - Statement of aims and actions 2009 [online]. Available from http://www.defra.gov.uk/environment/waste/topics/ documents/commercialindustrial-waste-aims-actions-091013.pdf. [Accessed date: 19 July 2010]

Defra (2010). Consultation on meeting EU Landfill Diversion Targets [online]. Available from: http://www.defra.gov.uk/corporate/consult/landfilldiversion/index.htm [Accessed date: 19 July 2010]

Jacobs Babtie, 2005. Project Integra. Maximising Collection Efficiency, DEFRA Waste Implementation Programme Local Authority Support Unit 
Jones, A, Nesaratnam, S and Porteous, A., 2008. The Open University Household Waste Survey. Fact Sheet No.2 Factors which influence household waste generation [online]. Report undertaken for DEFRA. Available from http://www.defra.gov.uk/evidence/statistics/environment/waste/research/down load/ou-fct02-20081008.pdf. [Accessed date: 19 July 2010]

Maynard, S. and Cherrett, T.J., 2009. Characteristics of retail waste logistics on Winchester High Street [online]. Green Logistics WM10 Report. Available from http://www.greenlogistics.org/PageView.aspx? id=202. [Accessed date: 19 July 2010]

Maynard S., Cherrett, T.J. and Waterson, B.J., 2009a. Monitoring Household Waste Recycling Centres performance using mean bin weight analyses. International Journal of Integrated Waste Management, Science and Technology, 29(2), 614-620.

Maynard S., Cherrett, T.J. and Waterson, B.J., 2009b. Gauging HWRC performance from vehicle weight ticket data. Proceedings of Institution of Civil Engineering, Waste and Resource Management, 162(1), 37-43.

Mazzotti, A., 2004. A critical assessment of a routeing and scheduling application for optimising household waste collections in Hampshire. M.Sc. dissertation, University of Southampton.

McLeod, F. N. and Cherrett, T.J., 2007. Maximising efficiency in household waste collection through improved fleet management. Proceedings of the Logistics Research Network Annual Conference, Hull, UK.

McLeod, F.N. and Cherrett, T.J., 2011. Appraisal of waste collection routeing and scheduling. Proceedings of the ICE - Waste and Resource Management, Vol. 164 , in press.

McLeod, F.N., Hickford, A., Maynard, S., Cherrett, T. and Allen, J., 2008. Developing innovative and more sustainable approaches to reverse logistics for the collection, recycling and disposal of waste products from urban centres [online]. Green Logistics WM10 report. Available from http://www.greenlogistics.org/PageView.aspx?id=43\&tid=43. [Accessed date: 19 July 2010].

Toth, P.and Vigo, D., 2002. Models, relaxations and exact approaches for the capacitated vehicle routing problem. Discrete Applications of Mathematics, 123, No. 1-3, 487-512. 